\title{
Genetic Architecture of Familial Hypercholesterolaemia
}

\author{
Mahtab Sharifi $^{1,2} \cdot$ Marta Futema $^{1} \cdot$ Devaki Nair $^{2} \cdot$ Steve E. Humphries $^{1}$ \\ Published online: 13 April 2017 \\ (C) The Author(s) 2017. This article is published with open access at Springerlink.com
}

\begin{abstract}
Purpose of Review Familial hypercholesterolaemia (FH) is an inherited disorder of low-density lipoprotein cholesterol (LDL-C) which is characterised by a raised cholesterol level from birth and a high risk of premature coronary heart disease. In this paper, we review the genetic basis of FH and its impact on the clinical presentation.

Recent Findings Mutations in any of three genes ( $L D L R$, $A P O B$ and $P C S K 9$ ) are known to cause autosomal dominant $\mathrm{FH}$, but a mutation can be found in only $\sim 40 \%$ of patients with a clinical diagnosis of FH. In the remainder, a polygenic aetiology is most likely, due to the co-inheritance of common LDL-C-raising variants. The cardiovascular presentation and management of $\mathrm{FH}$ will differ between patients based on their underlying genetic factors.

Summary New genotyping methods such as next-generation sequencing will provide us with better understanding of the genetic architecture of FH.
\end{abstract}

Keywords Familial hypercholesterolaemia $\cdot$ Polygenic hypercholesterolaemia $\cdot L D L R$ gene $\cdot A P O B$ gene $\cdot P C S K 9$ gene

This article is part of the Topical Collection on Lipid Abnormalities and Cardiovascular Prevention

Steve E. Humphries

steve.humphries@ucl.ac.uk

1 Institute of Cardiovascular Science, University College London, 5 University St, London WC1E 6JF, UK

2 Department of Clinical Biochemistry, the Royal Free London NHS Foundation Trust, Pond Street, London NW3 2QG, UK

\section{Introduction}

There are three available criteria for clinical diagnosis of Familial hypercholesterolaemia (FH): the Simon Broome criteria from the UK, the Dutch Lipid Clinic Network criteria from the Netherlands and the MedPed criteria from the USA (Table 1) [2]. In the UK, the National Institute for Health and Care Excellence (NICE) guideline recommends use of the Simon Broome criteria. These criteria include raised cholesterol levels, physical stigmata e.g. tendon xanthomata or an evidence of these signs in first- or second-degree relatives, and having a family history of premature coronary artery disease [3]. A 'definite' diagnosis of FH is made if a patient has elevated cholesterol levels and tendon xanthomata or a mutation is found by sequencing a DNA sample from the patient. A 'possible' diagnosis of FH is made if the patient has only high levels of cholesterol levels and a family history of hypercholesterolaemia or premature coronary heart disease (CHD). The Dutch Lipid Clinic Network criteria use a point system based on patient's cholesterol levels, personal and family history of premature coronary artery disease, physical examination and detected mutations to give a possible, probable or definite diagnosis of FH [2]. The Dutch Lipid Clinic Network criteria have been modified by clinicians in Wales to take into account that an elevated triglyceride level in a suspected FH patient makes it less likely that the patient has monogenic FH [1•]. Finally, the MedPed criteria are used for diagnosis of probable FH in the USA and are mainly based on the total cholesterol and low-density lipoprotein cholesterol (LDL-C) cut offs stratified by age and family history. The cut offs are different in individuals with first-, second- and third-degree relatives with FH [4].

Since FH is a disorder of LDL-C metabolism, it is important to understand the basic process of this pathway. 
Table 1 Simon Broome and Dutch Lipid Clinic Network diagnostic criteria for FH diagnostic criteria for index FH individuals

Simon Broome criteria

Diagnosis of definite FH

Cholesterol concentration (adults $>7.5 \mathrm{mmol} / 1 \mathrm{LDL}-\mathrm{C}^{\mathrm{a}}>4.9 \mathrm{mmol} / \mathrm{l}$ and children $>6.7 \mathrm{mmol} / \mathrm{l}, \mathrm{LDL}-\mathrm{C}>4.0 \mathrm{mmol} / \mathrm{l})$

And tendon xanthomata

Or DNA-based evidence of a mutation in the $L D L R, A P O B$ or PCSK9 genes

Diagnosis of possible FH

Cholesterol concentration (adults $>7.5 \mathrm{mmol} / 1 \mathrm{LDL}-\mathrm{C}^{\mathrm{a}}>4.9 \mathrm{mmol} / \mathrm{l}$ and children $>6.7 \mathrm{mmol} / \mathrm{l}$, LDL-C $>4.0 \mathrm{mmol} / \mathrm{l})$

And at least one of the following below:

Family history of myocardial infarction: aged younger than 50 years in second-degree relative or aged younger than 60 years in first-degree relative

And/or

Family history of raised total cholesterol greater than $7.5 \mathrm{mmol} / 1$ in adult first- or second-degree relative or greater than $6.7 \mathrm{mmol} .1$ in child, brother or sister aged younger than 16 years

Dutch Lipid Clinic Network criteria

Family history

First-degree relative with known premature (men $<55$ years and women $<60$ years) coronary and vascular disease or first-degree relative with known LDL-C above the 95th percentile

First-degree relative with tendon xanthomata and/or arcus cornealis, or children aged less than 18 years with LDL-C above the 95th percentile

Clinical history

Patient with premature coronary artery disease

Patient with premature cerebral or peripheral vascular disease

Physical examination

Tendon xanthomata

Arcus cornealis prior to age 45 years

Cholesterol levels

LDL-C $\geq 8.5$

LDL-C $6.5-8.4$

LDL-C 5.0-6.4

LDL-C $4.0-4.9$

1

DNA analysis

Functional mutation in the $L D L R$ gene

A 'definite' diagnosis requires more than 8 points

A 'probable' diagnosis requires $6-8$ points

A 'possible' diagnosis requires $3-5$ points

Dutch Lipid Clinic Network criteria modified by clinicians in Wales

Dutch Lipid Clinic Network criteria plus fasting triglyceride levels

$2.5-3.4 \mathrm{mmol} / 1$

$3.5-4.9 \mathrm{mmol} / 1$

$-2$

$-3$

$>5.0 \mathrm{mmol} / 1$

$-4$

Genetic testing offered when score- 6 points

a If untreated, LDL- C values are unobtainable, see the 'Correction Factor Table' in Haralambos et al. [1•] and calculate estimated value

LDL-C particles are comprised of an apoB molecule which envelopes a core of cholesteryl esters and triacylglycerols, together with smaller amounts of other lipid species. During normal lipid regulation, these particles bind to LDL-receptors expressed on the liver surface via their apoB molecule. The binding of LDL-C to its receptor induces a rapid internalisation of the LDL-C particlereceptor complex into the endosome compartment of the cell, where the lipoprotein is broken down into its constituent lipids and amino acids. The LDL-receptor then is either recycled back to the plasma membrane, or diverted to a lysosome and catabolised, so that the LDL-receptor is no longer available for recycling. Defects in any of these processes can therefore potentially cause $\mathrm{FH}$.

\section{FH-Causing Genes}

\section{The Low-Density Lipoprotein Receptor}

The $L D L R$ gene was the first gene found where mutations cause FH. It spans $45 \mathrm{~kb}$ (kilobases) on the short arm of chromosome 19 and comprises 18 exons that are transcribed and translated into five distinct domains which form the cell surface LDL-receptor [5]. Any defect in the LDLR gene can cause loss of function of LDL-receptors resulting in reduced LDL-C uptake from blood and cause FH. In mutation carriers, blood cholesterol level is usually raised two fold above the normal level. In the homozygous form, where two identical mutations have been inherited, one from each parent (usually 
from a consanguineous marriage), or compound heterozygous FH, where two different mutations on both alleles have been inherited, the cholesterol levels are four or five times greater than those of the heterozygous cases [6].

FH-causing mutations in the $L D L R$ gene are found along the entire length of the gene. There are more than 2900 different variants identified in the $L D L R$ gene with majority of them being exonic substitutions and small $(<100 \mathrm{bp})$ or large rearrangements (>100 bp) [7••]. More than $90 \%$ of the reported variants are likely to be disease causing [8]. Most FH cohort studies showed that among the variants found, a large proportion cluster in exon 4 [9]. This could be due to the large size of exon 4 or to the highly detrimental effect of variants in this exon which encodes the ligand-binding domain, on the gene function compared to variants in other exons. Patients with a mutation in exon 4 might present with more severe $\mathrm{FH}$ in the clinics. In contrast, the mutation frequency in exons 15 and 16 is extremely low. The spectrum of FH mutations varies between countries; from Greece, where a relatively small numbers of mutations account for the majority of FH cases, to the Netherlands where the mutation spectrum was found to be extensive [10]. The cause of FH in the UK is highly heterogeneous with over 200 different mutations reported [11, 12] The information regarding molecular diagnosis of $\mathrm{FH}$ in some parts of the world such as Latin America and South Asia are scant. In Brazil and Mexico, the countries with the largest cohorts in Latin America, only few LDLR mutations have been found that have been encountered in the European population previously [13].

Predicting whether novel variants in $L D L R$ are pathogenic or not is not always straightforward, especially for synonymous and missense variants. In 2013, the Association for Clinical Genetic Science (ACGS) published guidelines for the classification of variants, with categories ranging from 1 and 2 (clearly not or unlikely to be pathogenic), to 3 (variants of unknown significance), to 4 and 5 (likely to be or clearly pathogenic). The recently updated $L D L R$ variant database with variants classified according to these guidelines may be accessed via: http://databases.lovd.nl/shared/genes/LDLR [7••]. All 128 nonsense substitutions, 336 small frameshifting rearrangements and 116/117 large rearrangements were considered to be pathogenic (classes 4 and 5). Of the 795 missense variants analysed, 115were in classes 1 and 2, 605 in class 4 and 75 in class 3 . One hundred eleven of the 180 intronic variants, 4 of 34 synonymous variants and 14 of 37 reported promoter variants were predicted to be likely or clearly pathogenic (classes 4 and 5). It is clearly of great importance to be able to assess whether variants identified in clinical settings or as incidental findings in genomics projects are pathogenic or not. Although 93\% (1588) of LDLR variants in the current upgrade of the database have been assigned to an ACGS pathogenicity category, 7\% (115) remain as variants of unknown significance. It is hoped that as more information becomes available from in vitro functional studies, the development of additional in silico tools and from the various genomics studies, it will be possible to determine the pathogenicity of these variants, and indeed the classification of some variants may also change as our knowledge increases. The 'gold standard' test for pathogenicity of a variant is to carry out co-segregation studies, where the co-inheritance of the variant with elevated LDL-C levels is seen in many relatives in a family, while the relatives without the inherited variant have normal levels of LDL-C. The interpretation of family data may be complicated by the overlay of environmental factors that influence lipid levels and by the presence in the family of other genetic variants that raise or lower LDL-C.

\section{Apolipoprotein B}

Apolipoprotein B (apoB) is the major apolipoprotein on lipoprotein molecules, especially LDL-C, and functions as a ligand to the LDL-receptor. The gene is located on chromosome $2 \mathrm{p}$ and spans more than $43 \mathrm{~kb}$. The gene comprises 29 exons and is transcribed and translated into a protein of 4563 amino acids [14]. While truncation mutations in the $A P O B$ gene cause hypobetalipoproteinemia, mutations causing hypercholesterolaemia are due to missense mutations that result in ligand-defective apoB protein. The LDL-C particles made from this allele are therefore not able to bind to the LDLreceptor and thus accumulate in the blood [15]. A single mutation of the $A P O B$ gene (p.Arg3527Gln) accounts for approximately $6-10 \%$ of all $\mathrm{FH}$ cases in European population, and it is located in exon 26 of $A P O B$ gene [16]. Other $A P O B$ mutations in other regions of the gene such as p.Arg50Trp, p.Arg1164Thr and p.Gln4494del were also recently found to cause FH [17, 18•]. For other variants, for example for p.Arg3531Cys, which was detected in a patient with a clinical diagnosis of FH, while initial reports showed that LDL-C from the patient had reduced binding to the LDL-receptor, later co-segregation studies found that there was no clear cosegregation [19]. This variant is now considered to be a 'susceptibility' variant that raises the likelihood of hypercholesterolaemia in a carrier but does not itself cause frank FH.

\section{Proprotein Convertase Subtilisin/Kexin Type 9}

The PCSK9 (proprotein convertase subtilisin/kexin type 9) gene encodes an enzyme that is involved in regulating the degradation of the LDL-receptor protein in the lysosome of the cell, preventing it from being recycled to the cell surface. The gene is found on chromosome $1 \mathrm{p}$ and comprises 12 exons, covering $39 \mathrm{~kb}$ [20]. The PCSK9 molecule is synthesised as an inactive proprotein and undergoes cleavage in the endoplasmic reticulum to produce an enzyme with the prodomain noncovalently bound to the catalytic site, preventing further enzyme action. PCSK9 is secreted mostly 
from the liver and its binding to the LDL-receptor directs the receptor to the lysosome for degradation [21].

Mutations in the PCSK9 gene that cause FH are gain-offunction mutations that increase LDL-receptor degradation and consequently reduce the number of receptors on the cell surface. Although more than 20 such variants have been reported world-wide, the only common PCSK9 variant in the UK is p.Asp374Tyr, which occurs in about $2 \%$ of the mutation-positive FH patients. This variant is associated with a raised cholesterol level and a high risk of developing premature coronary heart disease, compared with a mutation in the LDLR gene [22]. On the other hand, lossof-function mutations that inactivate the PCSK9 protein lead to less degradation of the LDL-receptor [23]. The most common of these variants, p.Arg46Leu, enhances the clearance of LDL-C from the plasma and lowers cholesterol level in the plasma. In European populations, approximately $3 \%$ of individuals are carriers of this variant, and because of their lifelong lower LDL-C levels, they have $\sim 28 \%$ lower CHD risk [24].

\section{Other Monogenic Causes of FH}

A very rare autosomal recessive hypercholesterolaemia is caused by mutations in the low-density lipoprotein receptor adaptor protein 1 (LDLRAP1) gene which encodes a cytosolic protein that interacts with the cytoplasmic tail of the LDL-receptor. Mutations in this gene that usually cause premature truncations of the protein lead to LDLreceptor malfunction and hypercholesterolaemia. This gene is located on the short arm of chromosome 1 [25]. The LDL-C level in these cases is typically intermediate between homozygote and heterozygote autosomal dominant $\mathrm{FH}$ patients [2].

Several studies have reported that a specific mutation (p.Leu167del) in APOE gene causes autosomal dominant FH [26]. This mutation has been previously reported to be associated with sea-blue histiocytosis and familial combined hyperlipidaemia $(\mathrm{FCH})$ but overlap between the $\mathrm{FCH}$ and $\mathrm{FH}$ phenotype has been shown before as hypertriglyceridemia can be seen due to many common genetic and environmental factors $[27,28]$.

Several studies have been conducted to identify new genes causing $\mathrm{FH}$, using family studies and nextgeneration sequencing (NGS) and this has identified three genes STAP1 (signal transducing adaptor protein family 1), LIPA (lysosomal acid lipase) and PNPLA5 (patatin-like phospholipase-domain-containing family) where mutations may be causing significantly elevated LDL-C and possibly the clinical phenotype of FH [29•, 30, 31]. So far, for STAP1 and PNPLA5, these genes and variants in them have yet to be independently confirmed as FH-causing.

\section{Frequency of FH}

Next-generation sequencing has driven major advances in our understanding of monogenic cause of elevated LDL-C and premature $\mathrm{CHD}$, focussing on the three proven $\mathrm{FH}$-causing genes ( $L D L R, A P O B$ and PCSK9). Although the prevalence of FH has historically been estimated at $1 / 500$, the likely true prevalence of $\mathrm{FH}$-causing mutation carriage now appears to be between 1/250 and 1/300 in many European populations. In Denmark, 98,098 participants from the Copenhagen General Population Study were genotyped for the three common $L D L R$ mutations and commonest $A P O B$ mutation (p.Arg3527Gln). The prevalence of the four FH mutations was $1 / 565$, accounting for $\sim 39 \%$ of pathogenic mutations in the country, and equating to a total prevalence of FH-mutation carriers of $1 / 217[32 \bullet \bullet]$. A similar prevalence was reported in subjects in the UK 10,000 genome project [33], and in a large sample of healthy subjects in the USA [34]. In support of this higher estimate, although historically the prevalence of homozygote FH is believed to be 1 per million [6], several population-based studies have now estimated the prevalence to be around $1 / 300$ with a mean LDL-C levels prior to lipidlowering treatment being $12.9 \pm 5.1 \mathrm{mmol} / 1$. [35] This higher figure would be expected if the true prevalence of $\mathrm{FH}$ mutation carriers is $1 / 250$.

The frequency of heterozygous FH is also considerably higher in some populations due to founder effect. This occurs when immigration of a small number of subjects to a geographical area is followed by a population expansion from those individuals. If, by any chance, those individuals have $\mathrm{FH}$, then genetic drift could lead to a high proportion of affected people in that population. Such founder effects have been reported in French Canadian, South AfricanAfrikaners, Jews and Indians and Finns [2].

\section{Polygenic versus Monogenic FH}

In diagnostic laboratories, a mutation in one of the three known FH-causing genes can be found in $60-80 \%$ of patients with a clinical diagnosis of definite $\mathrm{FH}$ and $30 \%$ of patients with possible FH [11]. As shown in Fig. 1, mutations that cause loss of function in $L D L R$ or $A P O B$ or gain of function in $P C S K 9$ result in an individual moving from a low point in the population cholesterol distribution to being over the diagnostic cut-off for FH $(7.5 \mathrm{mmol} / \mathrm{l})$. In those where a causative mutation cannot be found, there is a strong possibility that there may be a polygenic cause for FH. The Global Lipids Genetics Consortium meta-analysis identified over 100 loci where common variants influence LDL-C levels [36]. Thus, in patients where no mutation can be found, the LDL-C and total cholesterol level is raised above the $\mathrm{FH}$ diagnostic cut-off by having inherited a greater than average number of common 


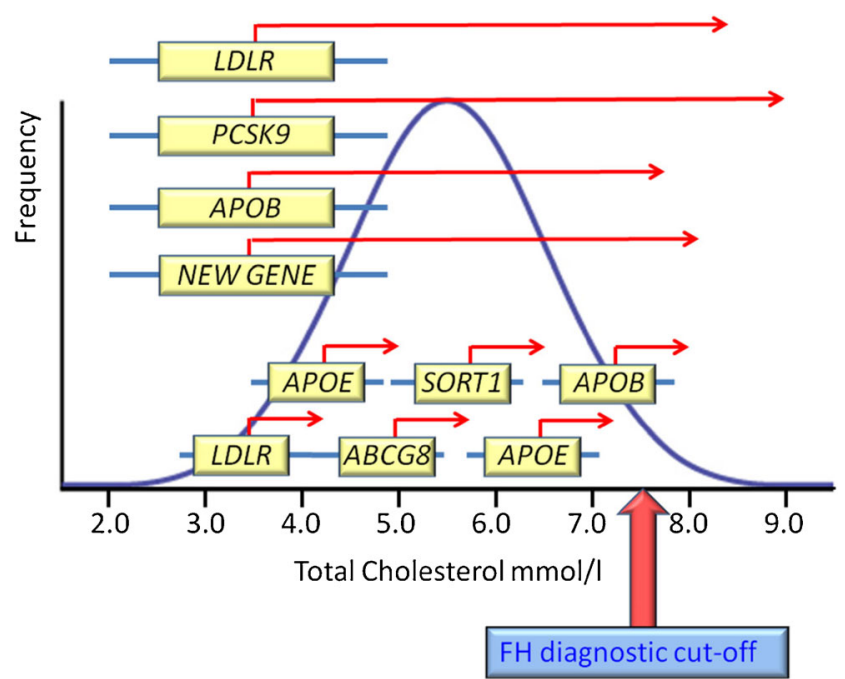

Fig. 1 Monogenic and polygenic causes of elevated plasma total cholesterol. Mutations that cause loss of function in LDLR or APOB or gain of function in PCSK9 result in an individual moving from a low point in the population cholesterol distribution to being over the diagnostic cut-off for familial hypercholesterolaemia $(7.5 \mathrm{mmol} / \mathrm{l})$. Mutations in PCSK9 are the most severe and in APOB, the mildest. The possibility that mutations in STAP1 may cause FH is shown. These individuals have 'monogenic FH.' It is also possible to have total cholesterol levels above the FH diagnostic cut-off by having inherited a greater than average number of common cholesterol-raising variants (SNP2, SNP2 etc) each of modest effect. As shown in (5), key SNPs are in LDLR, APOB, APOE $(2 \times)$ ABCG 8 and SORT1. These individuals have a 'polygenic' cause of their hypercholesterolaemia. In more than $80 \%$ of those with a clinical diagnosis of $\mathrm{FH}$ but with no detectable mutation in LDLR/APOB/PCSK9, the polygenic explanation is most likely. In the remainder, mutation in a novel gene may be present

cholesterol-raising variants with modest effect. Such key single nucleotide polymorphisms (SNPs) are located in $L D L R$, $A P O B, A P O E, A B C G 8$ and SORT1. In more than $80 \%$ of those with a clinical diagnosis of FH but with no detectable mutation in $L D L R / A P O B / P C S K 9$, the polygenic explanation is most likely. In the remainder, mutation in a novel gene may be present $[37 \bullet \bullet, 38 \bullet$.

The additional polygenic contribution might explain the variation in the LDL-C concentrations among the family members of the FH patients. In these families, it might be possible that the FH phenotype is caused by the combination of a single mutation of large effect in $L D L R / A P O B / P C S K 9$ and several LDL-C alleles of modest effect which may differ in the family members $[37 \bullet \bullet]$.

\section{Cascade Testing}

All recent European guidelines for the management of $\mathrm{FH}$ patients have recommended that healthcare professionals should offer a referral for cascade testing to every FH patient to identify affected first- and second- degree relatives of the index patient $[3,39]$. DNA testing would thus confirm the diagnosis of FH and helps to identify affected relatives at an early age. Lipid-lowering therapy in these individuals results in reducing the morbidity and mortality from premature CHD and would be a highly cost-effective strategy in the health services [40, 41]. Such cascade testing of the relatives of affected individuals has been carried out effectively in several countries in Europe, including Holland, and shown to be feasible in the UK [40].

The ascertainment of index cases in the UK is currently relying on a case presenting with premature CHD or the incidental finding of an extreme total cholesterol (TC) or LDL-C level. One problem is that TC and LDL-C values in adults with $\mathrm{FH}$ overlap substantially with values observed among individuals from the general population, where a higher than average burden of common, small-effect cholesterol-raising alleles can mimic the biochemical features of FH [37••]. Thus, biochemical screening for $\mathrm{FH}$ in adulthood is prone to misclassification. For this reason, according to recent surveys and a national audit, the FH patients currently treated by lipid clinics in the UK represent $<15 \%$ of an estimated $126,000 \mathrm{FH}$ patients in the UK (if the incidence of $1 / 500$ ) or $<7.5 \%$ of the estimated 252,000 FH patients (if the true incidence is $1 / 250$ ).

\section{Reverse Cascade Testing}

Wald and colleagues used the diagnostic criteria of either total cholesterol $>5.31 \mathrm{mmol} / 1$ (95th percentile) plus one mutation, or two cholesterol values of $\geq 5.90 \mathrm{mmol} / \mathrm{l}$ (99th percentile), in 10,094 children in the UK at the time of routine immunisations (median age 12.7 months) to identify adults with FH by measuring cholesterol level [42••]. They identified 45 children with $\mathrm{FH}$, including 37 with a detected mutation and 8 with a raised LDL-C but with no mutation. The prevalence of mutation carriers was estimated at $1 / 273(37 / 10,940)$. We have previously demonstrated that such individuals (without a monogenic cause of $\mathrm{FH}$ ) are likely to have a polygenic aetiology for their $\mathrm{FH}$ phenotype, with co-inheritance of a greater than average number of common LDL-C-raising variants of modest effect, and have proposed that only those patients with a detected mutation should be designated as monogenic FH. Testing parents of the confirmed FH children identified 40 parents who also met the criteria for FH diagnoses.

In the UK, in FH patients where a monogenic cause is found, roughly $93 \%$ have a mutation in the $L D L R$ gene, $5 \%$ in $A P O B$ and $2 \%$ in PCSK9 [43]. In the Wald study, $40 \%$ of the detected FH-mutations were the $A P O B$ (p.Arg3527Gln) mutation which is known to cause a generally less severe FH than most $L D L R$ mutations. Thus, while this screening approach has value in finding new families with $\mathrm{FH}$, it will also identify individuals with less severe form of hypercholesterolaemia and at lower cardiovascular risk. In these patients, the genetic data may contribute to decision-making for 
intensive statin treatment, but the risk-benefit balance is not as clear as for relatives of clinically diagnosed FH index cases, whose personal or family history of premature CHD is a key diagnostic component.

\section{Cardiovascular Disease in FH Patients with Different Genetic Cause of their Disease}

The earlier studies of heterozygous FH patients, before statin therapy became a standard treatment, showed the risk of fatal or nonfatal coronary heart disease by the age of 60 years was about $50 \%$ for male and $30 \%$ for females compared with $10 \%$ in the relatives without $\mathrm{FH}$ [2]. The concept of a cumulative LDL-C burden since birth may play an important role in the aetiology of cardiovascular disease in monogenic FH patients. Traditional cardiovascular risk factors such as age, male gender, smoking and hypertension may play additional roles to the genetic defects in increased coronary risk in these patients [44, 45].

Severity of the clinical presentations is different among the FH patients [39]. The severity and clinical expression of $\mathrm{CHD}$ are even variable within a family, where all relatives carry the same $L D L R$ gene defect [46-48]. The LDLR mutations (null allele) that severely impair the function of LDL-receptor are shown to cause more advanced CHD with earlier onset [46, $48,49]$. In addition, the severity of atherosclerosis appears to be greater in monogenic FH than that of polygenic hypercholesterolaemia $[50 \bullet, 51]$. Aortic valve and supravalve calcification is common among the FH patients with $L D L R$-negative mutations and homozygous $\mathrm{FH}[52,53]$.

This elevated risk for CHD in FH patients with a detected mutation has been convincingly confirmed by Khera et al. in a population-based analysis [54••]. Using NGS for the known FH genes among 20,485 CHD-free individuals, 1386 (6.7\%) had LDL-C $>4.9 \mathrm{mmol} / \mathrm{l}$, and of these, 24 (1.7\%) carried a known FH mutation. Compared with individuals with LDL-C $<3.7 \mathrm{mmol} / 1$ and no mutation, those with LDL-C $>4.9 \mathrm{mmol} / 1$ and no $\mathrm{FH}$ mutation had a six-fold higher risk for $\mathrm{CHD}$, but those with both LDL-C $>4.9 \mathrm{mmol} / \mathrm{l}$ and an FH mutation had a 22-fold higher risk. This risk is explained by the substantially higher accumulated 'LDL-C burden' since patients have had genetically determined lifelong high LDL-C.

\section{Conclusion}

Monogenic FH is mainly caused by mutations in common FH-causing genes. In patients with a clinical diagnosis of FH where no mutation found, it is most likely to be a polygenic cause for the clinical presentation. Using new genotyping methods such as NGS produces a large amount of sequence data which must be analysed using statistical and bioinformatics approaches and has increased the number of occasions where a variant of uncertain significance is identified. This creates a diagnostic conundrum which requires either in vitro molecular analysis to examine the impact on transcription or splicing, or co-segregation study of families to see if other relatives with the same variant have also high LDL-C levels. Better screening programmes for diagnosis of $\mathrm{FH}$ are needed in the community and for cascade testing of the relatives of the $\mathrm{FH}$ patients.

Acknowledgments Steve E. Humphries and Marta Futema are supported by a grant from the British Heart Foundation (BHF grant PG 08/ 008) and by funding from the Department of Health's NIHR Biomedical Research Centers funding scheme.

\section{Compliance with Ethical Standards}

Conflict of Interest Mahtab Sharifi declares that she has no conflict of interest.

Marta Futema reports speakers' fees from Sanofi.

Devaki Nair has received grants from Pfizer (Pfizer Foundation award 2008), Solvay, Merck Sharp \& Dohme, and Astra Zeneca. DN has advisory board membership with Merck Sharp \& Dohme, Sanofi, Amgen and Astra Zeneca.

Steve E. Humphries is the Medical director of a UCL spin-out company StoreGene that offers to clinicians genetic testing for patients with familial hypercholesterolaemia.

Human and Animal Rights and Informed Consent This article does not contain any studies with human or animal subjects performed by any of the authors.

Open Access This article is distributed under the terms of the Creative Commons Attribution 4.0 International License (http:// creativecommons.org/licenses/by/4.0/), which permits unrestricted use, distribution, and reproduction in any medium, provided you give appropriate credit to the original author(s) and the source, provide a link to the Creative Commons license, and indicate if changes were made.

\section{References}

Papers of particular interest, published recently, have been highlighted as:

- Of importance

•. Of major importance

1. Haralambos K, Whatley SD, Edwards R, Gingell R, Townsend D, Ashfield-Watt $\mathrm{P}$, et al. Clinical experience of scoring criteria for familial hypercholesterolaemia $(\mathrm{FH})$ genetic testing in Wales. Atherosclerosis. 2015;240(1):190-6. doi:10.1016/j. atherosclerosis.2015.03.003. Modification of the Dutch Lipid Clinic Network scoring system by subtracting points for the degree of elevation of fasting triglycerides has shown to improve mutation detection rate.

2. Austin MA, Hutter CM, Zimmern RL, Humphries SE. Genetic causes of monogenic heterozygous familial hypercholesterolemia: a huge prevalence review. Am J Epidemiol. 2004;160(5):407-20. doi:10.1093/aje/kwh236. 
3. DeMott KNL, Shaw EJ, Minhas R, Humphries SE, Kathoria M, Ritchie $\mathrm{G}$, et al. Clinical guidelines and evidence review for familial hypercholesterolaemia: the identification and management of adults and children with familial hypercholesterolaemia. London: National Collaborating Centre for Primary Care and Royal College of General Practitioners; 2008.

4. Williams RR, Hunt SC, Schumacher MC, Hegele RA, Leppert MF, Ludwig EH, et al. Diagnosing heterozygous familial hypercholesterolemia using new practical criteria validated by molecular genetics. Am J Cardiol. 1993;72(2):171-6.

5. Hobbs HH, Brown MS, Goldstein JL. Molecular genetics of the LDL receptor gene in familial hypercholesterolemia. Hum Mutat. 1992;1(6):445-66. doi:10.1002/humu.1380010602.

6. Cuchel M, Bruckert E, Ginsberg HN, Raal FJ, Santos RD, Hegele RA, et al. Homozygous familial hypercholesterolaemia: new insights and guidance for clinicians to improve detection and clinical management. A position paper from the consensus panel on familial hypercholesterolaemia of the European Atherosclerosis Society. Eur Heart J. 2014;35(32):2146-57. doi:10.1093/eurheartj/ehu274.

7.• Leigh S, Futema M, Whittall R, Taylor-Beadling A, Williams M, den Dunnen JT, et al. The UCL low-density lipoprotein receptor gene variant database: pathogenicity update. J Med Genet. 2016; doi:10.1136/jmedgenet-2016-104054. This study updates the $L D L R$ variants database available for use by scientists and clinicians, giving clear pathogenic or non-pathogenic catagories to over 1000 published variants.

8. Usifo E, Leigh SE, Whittall RA, Lench N, Taylor A, Yeats C, et al. Low-density lipoprotein receptor gene familial hypercholesterolemia variant database: update and pathological assessment. Ann Hum Genet. 2012;76(5):387-401. doi:10.1111/j. 1469-1809.2012.00724.x.

9. Grenkowitz T, Kassner U, Wuhle-Demuth M, Salewsky B, Rosada A, Zemojtel T, et al. Clinical characterization and mutation spectrum of German patients with familial hypercholesterolemia. Atherosclerosis. 2016;253:88-93. doi:10.1016/j.atherosclerosis. 2016.08.037.

10. Kusters DM, Huijgen R, Defesche JC, Vissers MN, Kindt I, Hutten BA, et al. Founder mutations in the Netherlands: geographical distribution of the most prevalent mutations in the low-density lipoprotein receptor and apolipoprotein B genes. Neth Heart J. 2011;19(4):175-82. doi:10.1007/s12471-011-0076-6.

11. Taylor A, Wang D, Patel K, Whittall R, Wood G, Farrer M, et al. Mutation detection rate and spectrum in familial hypercholesterolaemia patients in the UK pilot cascade project. Clin Genet. 2010;77(6):572-80. doi:10.1111/j.1399-0004.2009.01356.x.

12. Futema M, Whittall RA, Kiley A, Steel LK, Cooper JA, Badmus E, et al. Analysis of the frequency and spectrum of mutations recognised to cause familial hypercholesterolaemia in routine clinical practice in a UK specialist hospital lipid clinic. Atherosclerosis. 2013;229(1):161-8. doi:10.1016/j.atherosclerosis.2013.04.011.

13. Mehta R, Zubiran R, Martagon AJ, Vazquez-Cardenas A, SeguraKato Y, Tusie-Luna MT, et al. The panorama of familial hypercholesterolemia in Latin America: a systematic review. J Lipid Res. 2016;57(12):2115-29. doi:10.1194/jlr.R072231.

14. Chen SH, Yang CY, Chen PF, Setzer D, Tanimura M, Li WH, et al. The complete cDNA and amino acid sequence of human apolipoprotein B-100. J Biol Chem. 1986;261(28):12918-21.

15. Myant NB. Familial defective apolipoprotein B-100: a review, including some comparisons with familial hypercholesterolaemia. Atherosclerosis. 1993;104(1-2):1-18.

16. Myant NB, Forbes SA, Day IN, Gallagher J. Estimation of the age of the ancestral arginine 3500 $\rightarrow$ glutamine mutation in human apoB100. Genomics. 1997;45(1):78-87. doi:10.1006/geno.1997.4898.

17. Fernandez-Higuero JA, Etxebarria A, Benito-Vicente A, Alves AC, Arrondo JL, Ostolaza H, et al. Structural analysis of APOB variants, p.(Arg3527Gln), p.(Arg1164Thr) and p.(Gln4494del), causing familial hypercholesterolaemia provides novel insights into variant pathogenicity. Sci Rep. 2015;5:18184. doi:10.1038/srep18184.

18. Thomas ER, Atanur SS, Norsworthy PJ, Encheva V, Snijders AP, Game L, et al. Identification and biochemical analysis of a novel APOB mutation that causes autosomal dominant hypercholesterolemia. Mol Genet Genomic Med. 2013;1(3):155-61. doi:10.1002/ mgg3.17. Identification of a novel FH-causing $A P O B$ mutation that is outside the LDL-binding region of the protein.

19. Rabes JP, Varret M, Devillers M, Aegerter P, Villeger L, Krempf M, et al. R3531C mutation in the apolipoprotein B gene is not sufficient to cause hypercholesterolemia. Arterioscler Thromb Vasc Biol. 2000;20(10):E76-82.

20. Humphries SE, Neely RD, Whittall RA, Troutt JS, Konrad RJ, Scartezini M, et al. Healthy individuals carrying the PCSK9 p.R46L variant and familial hypercholesterolemia patients carrying PCSK9 p.D374Y exhibit lower plasma concentrations of PCSK9. Clin Chem. 2009;55(12):2153-61. doi:10.1373/clinchem.2009.129759.

21. Lagace TA, Curtis DE, Garuti R, McNutt MC, Park SW, Prather HB, et al. Secreted PCSK9 decreases the number of LDL receptors in hepatocytes and in livers of parabiotic mice. J Clin Invest. 2006;116(11):2995-3005. doi:10.1172/JCI29383.

22. Naoumova RP, Tosi I, Patel D, Neuwirth C, Horswell SD, Marais $\mathrm{AD}$, et al. Severe hypercholesterolemia in four British families with the D374Y mutation in the PCSK9 gene: long-term follow-up and treatment response. Arterioscler Thromb Vasc Biol. 2005;25(12): 2654-60. doi:10.1161/01.ATV.0000190668.94752.ab.

23. Zhao Z, Tuakli-Wosornu Y, Lagace TA, Kinch L, Grishin NV, Horton JD, et al. Molecular characterization of loss-of-function mutations in PCSK9 and identification of a compound heterozygote. Am J Hum Genet. 2006;79(3):514-23. doi:10.1086/507488.

24. Benn M, Nordestgaard BG, Grande P, Schnohr P, Tybjaerg-Hansen A. PCSK9 R46L, low-density lipoprotein cholesterol levels, and risk of ischemic heart disease: 3 independent studies and meta-analyses. J Am Coll Cardiol. 2010;55(25):2833-42. doi:10.1016/j.jacc. 2010.02.044.

25. Michaely P, Li WP, Anderson RG, Cohen JC, Hobbs HH. The modular adaptor protein ARH is required for low density lipoprotein (LDL) binding and internalization but not for LDL receptor clustering in coated pits. J Biol Chem. 2004;279(32):34023-31. doi:10.1074/jbc.M405242200.

26. Marduel M, Ouguerram K, Serre V, Bonnefont-Rousselot D, Marques-Pinheiro A, Erik Berge K, et al. Description of a large family with autosomal dominant hypercholesterolemia associated with the APOE p.Leu167del mutation. Hum Mutat. 2013;34(1): 83-7. doi:10.1002/humu.22215.

27. Civeira F, Jarauta E, Cenarro A, Garcia-Otin AL, Tejedor D, Zambon D, et al. Frequency of low-density lipoprotein receptor gene mutations in patients with a clinical diagnosis of familial combined hyperlipidemia in a clinical setting. J Am Coll Cardiol. 2008;52(19):1546-53. doi:10.1016/j.jacc.2008.06.050.

28. Talmud PJ. Genetic determinants of plasma triglycerides: impact of rare and common mutations. Curr Atheroscler Rep. 2001;3(3):191-9.

29. Fouchier SW, Dallinga-Thie GM, Meijers JC, Zelcer N, Kastelein JJ, Defesche JC, et al. Mutations in STAP1 are associated with autosomal dominant hypercholesterolemia. Circ Res. 2014;115(6):552-5. doi:10.1161/CIRCRESAHA.115.304660. Identification of a potential new FH-causing gene in patients in Holland but not yet confirmed elsewhere.

30. Lange LA, Hu Y, Zhang H, Xue C, Schmidt EM, Tang ZZ, et al. Whole-exome sequencing identifies rare and low-frequency coding variants associated with LDL cholesterol. Am J Hum Genet. 2014;94(2):233-45. doi:10.1016/j.ajhg.2014.01.010.

31. Stitziel NO, Fouchier SW, Sjouke B, Peloso GM, Moscoso AM, Auer PL, et al. Exome sequencing and directed clinical phenotyping diagnose cholesterol ester storage disease presenting as 
autosomal recessive hypercholesterolemia. Arterioscler Thromb Vasc Biol. 2013;33(12):2909-14. doi:10.1161/ATVBAHA.113. 302426.

32.• Benn M, Watts GF, Tybjaerg-Hansen A, Nordestgaard BG. Mutations causative of familial hypercholesterolaemia: screening of 98098 individuals from the Copenhagen general population study estimated a prevalence of 1 in 217. Eur Heart J. 2016;37(17):1384-94. doi:10.1093/eurheartj/ehw028. The first European population-based molecular screening to establish the prevelance of $\mathrm{FH}$.

33. Consortium UK, Walter K, Min JL, Huang J, Crooks L, Memari Y, et al. The UK10K project identifies rare variants in health and disease. Nature. 2015;526(7571):82-90. doi:10.1038/nature14962.

34. Do R, Stitziel NO, Won HH, Jorgensen AB, Duga S, Angelica Merlini $\mathrm{P}$, et al. Exome sequencing identifies rare LDLR and APOA5 alleles conferring risk for myocardial infarction. Nature. 2015;518(7537):102-6. doi:10.1038/nature13917.

35. Sjouke B, Kusters DM, Kindt I, Besseling J, Defesche JC, Sijbrands EJ, et al. Homozygous autosomal dominant hypercholesterolaemia in the Netherlands: prevalence, genotype-phenotype relationship, and clinical outcome. Eur Heart J. 2015;36(9):560-5. doi:10. 1093/eurheartj/ehu058.

36. Teslovich TM, Musunuru K, Smith AV, Edmondson AC, Stylianou IM, Koseki M, et al. Biological, clinical and population relevance of 95 loci for blood lipids. Nature. 2010;466(7307):707-13. doi:10. 1038/nature09270.

37.• Talmud PJ, Shah S, Whittall R, Futema M, Howard P, Cooper JA, et al. Use of low-density lipoprotein cholesterol gene score to distinguish patients with polygenic and monogenic familial hypercholesterolaemia: a case-control study. Lancet. 2013;381(9874):1293301. doi:10.1016/S0140-6736(12)62127-8. This study explains the basis of polygenic hypercholesterolemia and the common LDL-C-raising variants causing it in a group of patients with a clinical diagnosis of $\mathrm{FH}$ where no mutation was found in the three common FH-causing genes.

38. Futema M, Shah S, Cooper JA, Li K, Whittall RA, Sharifi M, et al. Refinement of variant selection for the LDL cholesterol genetic risk score in the diagnosis of the polygenic form of clinical familial hypercholesterolemia and replication in samples from 6 countries. Clin Chem. 2015;61(1):231-8. doi:10.1373/clinchem.2014. 231365. This study confirms the polygenic contribution to non-mutation FH in 6 European countries and shows that the top 6 SNPs perform as well as the 12 SNPS used originally.

39. Nordestgaard BG, Chapman MJ, Humphries SE, Ginsberg HN, Masana L, Descamps OS, et al. Familial hypercholesterolaemia is underdiagnosed and undertreated in the general population: guidance for clinicians to prevent coronary heart disease: consensus statement of the European Atherosclerosis Society. Eur Heart J. 2013;34(45):3478-90a. doi:10.1093/eurheartj/eht273.

40. Hadfield SG, Horara S, Starr BJ, Yazdgerdi S, Marks D, Bhatnagar D, et al. Family tracing to identify patients with familial hypercholesterolaemia: the second audit of the Department of Health Familial Hypercholesterolaemia Cascade Testing Project. Ann Clin Biochem. 2009;46(Pt 1):24-32. doi:10.1258/acb.2008. 008094.

41. Humphries SE, Norbury G, Leigh S, Hadfield SG, Nair D. What is the clinical utility of DNA testing in patients with familial hypercholesterolaemia? Curr Opin Lipidol. 2008;19(4):362-8. doi:10. 1097/MOL.0b013e32830636e5.

42.• Wald DS, Bestwick JP, Morris JK, Whyte K, Jenkins L, Wald NJ. Child-parent familial hypercholesterolemia screening in primary care. N Engl J Med. 2016;375(17):1628-37. doi:10.1056/ NEJMoa1602777. Demonstration of the feasabilty of 'reverse cascade testing' by screening infants for high cholesterol and then testing their parents found a prevelance of $\mathrm{FH}$-mutation carriers in the UK of $\sim 1 / 270$.

43. Humphries SE, Whittall RA, Hubbart CS, Maplebeck S, Cooper JA, Soutar AK, et al. Genetic causes of familial hypercholesterolaemia in patients in the UK: relation to plasma lipid levels and coronary heart disease risk. J Med Genet. 2006;43(12):943-9. doi:10.1136/jmg.2006. 038356.

44. Hill JS, Hayden MR, Frohlich J, Pritchard PH. Genetic and environmental factors affecting the incidence of coronary artery disease in heterozygous familial hypercholesterolemia. Arterioscler Thromb. 1991;11(2):290-7.

45. Neil HA, Seagroatt V, Betteridge DJ, Cooper MP, Durrington PN, Miller JP, et al. Established and emerging coronary risk factors in patients with heterozygous familial hypercholesterolaemia. Heart. 2004:90(12):1431-7. doi:10.1136/hrt.2003.022764.

46. Ferrieres J, Lambert J, Lussier-Cacan S, Davignon J. Coronary artery disease in heterozygous familial hypercholesterolemia patients with the same LDL receptor gene mutation. Circulation. 1995;92(3):290-5.

47. Jarauta E, Junyent M, Gilabert R, Plana N, Mateo-Gallego R, de Groot E, et al. Sonographic evaluation of Achilles tendons and carotid atherosclerosis in familial hypercholesterolemia. Atherosclerosis. 2009;204(2):345-7. doi:10.1016/j.atherosclerosis. 2008.09.040.

48. Besseling J, Kindt I, Hof M, Kastelein JJ, Hutten BA, Hovingh GK. Severe heterozygous familial hypercholesterolemia and risk for cardiovascular disease: a study of a cohort of 14,000 mutation carriers. Atherosclerosis. 2014;233(1):219-23. doi:10.1016/j. atherosclerosis.2013.12.020.

49. Vilades Medel D, Leta Petracca R, Carreras Costa F, Cardona Olle M, Barros Membrilla A, Hidalgo Perez JA, et al. Coronary computed tomographic angiographic findings in asymptomatic patients with heterozygous familial hypercholesterolemia and null allele low-density lipoprotein receptor mutations. Am J Cardiol. 2013;111(7):955-61. doi:10.1016/j.amjcard.2012.12.012.

50. Sharifi M, Gallivan A, Harvey D, Li KW, Cooper J, Futema M, Humphries SE, Nair D. Atherosclerosis in monogenic familial hypercholesterolemia versus polygenic hypercholesterolemia. Atherosclerosis. 2016b;252:e36-e7. Pilot study demonstrating the higher carotid thickening in monogenic FH patients compared to that of matched polygenic patients.

51. Sharifi M, Jain A, Resuad J, Humphries SE, Nair D. Cardiovascular biomarkers in monogenic familial hypercholesterolaemia and polygenic hypercholesterolaemia. Atherosclerosis. 2016a;255:e4.

52. Santos RD, Miname MH, Martinez LR, Rochitte CE, Chacra AP, Nakandakare ER, et al. Non-invasive detection of aortic and coronary atherosclerosis in homozygous familial hypercholesterolemia by 64 slice multi-detector row computed tomography angiography. Atherosclerosis. 2008;197(2):910-5. doi:10.1016/j.atherosclerosis. 2007.08.017.

53. Rafeiyian S, Mojtahedzadeh S, Hekmat M, Naderi N, Nobahar R, Hashemi MJ, et al. Supravalvular and valvular aortic stenosis in heterozygous familial hypercholesterolemia. Med Princ Pract. 2007;16(4):315-7. doi:10.1159/000102156.

54.• Khera AV, Won HH, Peloso GM, Lawson KS, Bartz TM, Deng X, et al. Diagnostic yield and clinical utility of sequencing familial hypercholesterolemia genes in patients with severe hypercholesterolemia. J Am Coll Cardiol. 2016;67(22):2578-89. doi:10.1016/j. jacc.2016.03.520. This demonstrates the high CAD mortality rate in patients with an FH-causing mutation compared to patients with similarly elevated LDL-C but with no mutation. 